\title{
Efiects of p-Synephrine alone and in Combination with Selected Bioflavo- noids on Resting Metabolism, Blood Pressure, Heart Rate and Seli-Reported Mood Changes
}

\author{
Sidney J. Stohs ${ }^{1}$, Harry G Preuss ${ }^{2}{ }^{\bowtie}$, Samuel C. Keith ${ }^{3}$, Patti L. Keith ${ }^{3}$, Howard Miller ${ }^{4}$, Gilbert R. Kaats ${ }^{3}$ \\ 1. Dean Emeritus, Creighton University Health Sciences Center, Omaha, NE 68178, USA \\ 2. Department of Physiology, Georgetown University Medical Center, Washington, DC, USA \\ 3. Integrative Health Technologies, Inc., 4940 Broadway, San Antonio, TX 78209, USA \\ 4. Nutratech Inc., West Caldwell, NJ 07006, USA
}

Corresponding author: Harry G. Preuss, M.D., preusshg@georgetown.edu, phone: 1-202-687-1441

(c) Ivyspring International Publisher. This is an open-access article distributed under the terms of the Creative Commons License (http://creativecommons.org/ licenses/by-nc-nd/3.0/). Reproduction is permitted for personal, noncommercial use, provided that the article is in whole, unmodified, and properly cited.

Received: 2011.02.02; Accepted: 2011.03.06; Published: 2011.04.28

\begin{abstract}
Bitter orange (Citrus aurantium) extract is widely used in dietary supplements for weight management and sports performance. Its primary protoalkaloid is $p$-synephrine. Most studies involving bitter orange extract and $p$-synephrine have used products with multiple ingredients. The current study assessed the thermogenic effects of $p$-synephrine alone and in conjunction with the flavonoids naringin and hesperidin in a double-blinded, randomized, placebo-controlled protocol with 10 subjects per treatment group. Resting metabolic rates (RMR), blood pressure, heart rates and a self-reported rating scale were determined at baseline and 75 min after oral ingestion of the test products in V-8 juice. A decrease of $30 \mathrm{kcal}$ occurred in the placebo control relative to baseline. The group receiving $p$-synephrine $(50 \mathrm{mg})$ alone exhibited a $65 \mathrm{kcal}$ increase in RMR as compared to the placebo group. The consumption of $600 \mathrm{mg}$ naringin with $50 \mathrm{mg}$ p-synephrine resulted in a $129 \mathrm{kcal}$ increase in RMR relative to the placebo group. In the group receiving $100 \mathrm{mg}$ hesperidin in addition to the $50 \mathrm{mg} p$-synephrine plus $600 \mathrm{mg}$ naringin, the RMR increased by $183 \mathrm{kcal}$, an increase that was statistically significant with respect to the placebo control $(p<0.02)$. However, consuming $1000 \mathrm{mg}$ hesperidin with $50 \mathrm{mg} p$-synephrine plus $600 \mathrm{mg}$ naringin resulted in a RMR that was only $79 \mathrm{kcal}$ greater than the placebo group. None of the treatment groups exhibited changes in heart rate or blood pressure relative to the control group, nor there were no differences in self-reported ratings of 10 symptoms between the treatment groups and the control group. This unusual finding of a thermogenic combination of ingredients that elevated metabolic rates without corresponding elevations in blood pressure and heart-rates warrants longer term studies to assess its value as a weight control agent.
\end{abstract}

Key words: $p$-Synephrine, naringin, hesperidin, resting metabolic rate, heart rate, blood pressure

\section{Introduction}

The bioflavonoids hesperetin and naringenin are widely distributed in citrus fruits and juices as their glycosides, hesperidin and naringin, respectively. They are present in Citrus aurantium as well as a wide variety of other Citrus species [1]. The sugar moieties for both flavonoids consist of rhamnose plus glucose, which must be removed in the intestinal tract before the flavonoids can be absorbed [2,3]. The absorption 
of these flavonoids in human subjects has been extensively studied and depends in part upon the forms in which they are ingested (juice or fruit, glycoside or aglycone, capsule, tablet, etc.) [4-8].

Experiments involving human subjects, animals and cell culture systems have shown that the two flavonoids exhibit a wide range of potentially beneficial physiological and biochemical effects. Naringen and/or hesperidin or their aglycones have been shown to improve insulin sensitivity and glucose tolerance [9], prevent accumulation of triglycerides [9], inhibit cholesterol biosynthesis [10, 11], and serve as antioxidants and anti-inflammatory agents $[12,13]$ as well as hepatoprotectants [14] and neuroprotectants [15]. However, the effects of naringin and hesperidin on metabolic rate and energy utilization have not been previously assessed.

Studies have suggested that $p$-synephrine has thermogenic and lipolytic activities [16-18], increasing energy metabolism $[19,20]$ as well as athletic performance [21]. $p$-Synephrine is the primary protoalkaloid in bitter orange extract which is derived from the immature fruits of Citrus aurantium [22-25], and is widely distributed in other Citrus species [22, 23, 26]. The safety of $p$-synephrine and bitter orange extract has recently been reviewed [27], and based on the available studies in animals, humans and cell culture systems, it has been concluded that when taken orally and in recommended amounts both are safe.

$p$-Synephrine is widely used in combination with caffeine and other ingredients in products designed to support weight management $[19,28]$. However, no studies have been reported comparing the thermogenic effects of $p$-synephrine when combined with the flavonoids hesperidin and naringin. This pilot study was designed to examine these effects using a comparative effectiveness research (CER) study design
[29] in a double-blinded, randomized, placebo-controlled protocol to compare the effects of $p$-synephrine alone and in combination with different amounts of hesperidin and naringin on: (1) resting metabolism, (2) blood pressure, (3) resting heart-rate, and (4) self-reported mood/energy levels in healthy human subjects.

\section{Material and methods:}

A total of 50 participants gave written informed consent in compliance with the Helsinki Declaration and approved by Integrative Health Technologies' Ethics Committee. Participants fasted for 8-10 hours without consuming caffeinated beverages, nicotine, exercising or participating in vigorous physical activities. Upon reporting to the research center, participants completed the 10-item self report in Table 1.

After remaining seated in an isolated area for 10-15 min., participants completed measurements of their blood pressure, resting heart-rate and resting metabolism using Micro Life's MedGem ${ }^{\circledR}$ Indirect Calorimeter (Microlife Medical Home Solutions, Golden, CO. 80401). The MedGem ${ }^{\circledR}$ is a hand-held, self-calibrating calorimeter that measures oxygen consumption (VO2) to determine resting metabolic rate (RMR). In conjunction with the study, test-retest reliabilities of the instrument were measured on 41 subjects from test-retest periods ranging from 1-17 days between tests. The average reliability coefficient was $90.2 \%$, a coefficient that was consistent over the four test-retest periods.

$p$-Synephrine was administered in the form of the patented bitter orange extract Advantra $\mathrm{Z}^{\circledR}$ which contained $60 \%$ of this active material. Naringin and hesperidin were $96 \%$ pure. All test materials were obtained from Nutratech Inc. (West Caldwell, NJ).

Table I. Self Ratings Completed at Baseline, 45 and 75 minutes.

$\begin{array}{clll}1 & \text { Energy level } & \text { Very Low } & 1 \ldots 2 \ldots 3 \ldots 4 \ldots 5 \ldots \text { Very High } \\ 2 & \text { Hunger level } & \text { Very Low } & 1 \ldots 2 \ldots 3 \ldots 4 \ldots 5 \ldots \text { Very High } \\ 3 & \text { Concentration } & \text { Very Low } & 1 \ldots 2 \ldots 3 \ldots 4 \ldots 5 \ldots \text { Very High } \\ 4 & \text { Sleepiness } & \text { Very Low } & 1 \ldots 2 \ldots 3 \ldots 4 \ldots 5 \ldots \text { Very High } \\ 5 & \text { Upset stomach } & \text { Very Low } & 1 \ldots 2 \ldots 3 \ldots 4 \ldots 5 \ldots \text { Very High } \\ 6 & \text { Headache } & \text { Very Low } & 1 \ldots 2 \ldots 3 \ldots 4 \ldots 5 \ldots \text { Very High } \\ 7 & \text { Nervousness } & \text { Very Low } & 1 \ldots 2 \ldots 3 \ldots 4 \ldots 5 \ldots \text { Very High } \\ 8 & \text { Overall anxiety } & \text { Very Low } & 1 \ldots 2 \ldots 3 \ldots 4 \ldots 5 \ldots \text { Very High } \\ 9 & \text { Overal tension } & \text { Very Low } & 1 \ldots 2 \ldots 3 \ldots 4 \ldots 5 \ldots \text { Very High } \\ 10 & \text { General discomfort } & \text { Very Low } & 1 \ldots 2 \ldots 3 \ldots 4 \ldots 5 \ldots \text { Very High }\end{array}$


Subsequent to RMR measurements, participants were randomly assigned to one of the five double-blinded treatment conditions in which they consumed one ounce of V-8 juice containing the following ingredient variations:

Group 1: Placebo (V-8 juice only)

Group 2: Advantra $Z^{\circledR}$ (50 mg of $p$-synephrine)

Group 3: Advantra $Z^{\circledR}$ with $0 \mathrm{mg}$ hesperidin and $600 \mathrm{mg}$ naringin

Group 4: Advantra $\mathrm{Z}^{\circledR}$ with $100 \mathrm{mg}$ hesperidin and $600 \mathrm{mg}$ naringin

Group 5: Advantra $Z^{\circledR}$ with 1,000 mg hesperidin and $600 \mathrm{mg}$ naringin

After remaining seated and resting for $45 \mathrm{~min}$., participants completed a second self report rating scale. After $75 \mathrm{~min}$., a third and final self report rating scale was completed, and measurements of blood pressure, heart-rate and RMR were determined.

\section{Statistical Analyses}

ANOVAs were calculated between the groups' baseline, ending and change scores for each treatment group in addition to Dunnett's t-test between each of the treatment groups and the placebo group.

\section{Results}

Figure 1 shows the changes in resting metabolic rates (RMRs) from baseline expressed as kcals for each of the treatment groups ( $\mathrm{N}=10$ per group). As expected, a small decrease occurred in the RMR of the placebo group since these participants continued their 8-10 hour fast (Group1). Increases occurred in the RMR of all treatment groups. As compared to placebo, $50 \mathrm{mg} p$-synephrine (Advantra $\mathrm{Z}^{\circledR}$ ) alone (Group 2) more than doubled consumption by 65 kcals over placebo. In Group 3, adding $600 \mathrm{mg}$ naringin to the 50 mg $p$-synephrine further increased calorie consumption more than three-fold to $122 \mathrm{kcals}$ over placebo. The addition of $100 \mathrm{mg}$ hesperidin to the $p$-synephrine plus naringin in Group 4 resulted in a further increase in calorie consumption by 5 -fold to $183 \mathrm{kcal}$ over placebo. However, in Group 5, when the amount of hesperidin consumed in conjunction with the $50 \mathrm{mg}$ $p$-synephrine plus $600 \mathrm{mg}$ naringin was increased to $1000 \mathrm{mg}$, the increase in calorie consumption over placebo was only $79 \mathrm{kcal}$, an increase between calorie consumption in the absence of hesperidin and in the presence of $100 \mathrm{mg}$ hesperidin.

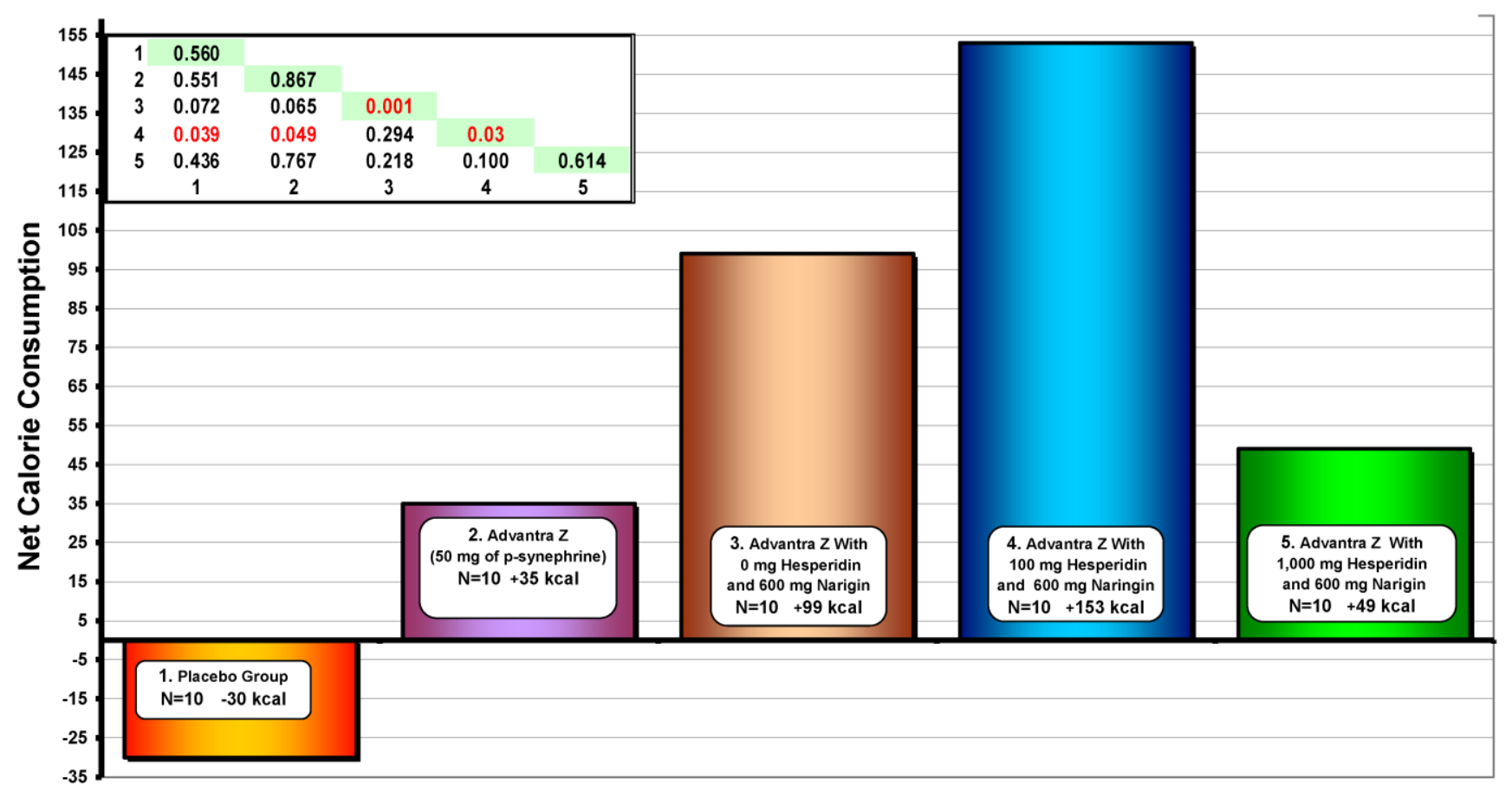

Figure I. Over-Placebo Comparisons of Changes in Resting Metabolic Rates 75 Minutes from Baseline (Expressed in kcal) With a Supplement Containing the Variations in Advantra Z, Naringin, and Hesperidin 
In spite of the low levels of statistical power in these groups of only 10 subjects, the increases in RMR in Group 4 was significantly greater than placebo $(\mathrm{P}=0.039)$ and Advantra $\mathrm{Z}$ alone (Group 2). It is also worth noting the a repeated-measures Students' $t$-test revealed that the changes from baseline in Group 3 and Group 4 were both statistically significant $(P=0.001$ and 0.030 , respectively).

Table 2 shows changes in blood pressures and resting heart-rates from baseline to the ending test for each of the five study groups. The average baseline blood pressures and resting heart-rates for the study cohort were well within the normal ranges of 121/74 $\mathrm{mm} \mathrm{Hg}$ and 70 BPM. At the conclusion of the study (75 min.), no increases in either systolic or diastolic blood pressures or heart rate were observed. None of the baseline-ending changes approached statistical significance nor were there any statistically significant differences between any of the five study groups.

Table 3 depicts the results of the self-report ratings for the 10 symptoms. As compared to the placebo group, none of the changes in these 10 self-reported symptoms were statistically significant either 45 or 75 min. from baseline. No significant effects relative to the placebo group were observed by the participants in the four treatment groups for symptoms including anxiety, hunger, tension, sleepiness, energy, nervousness, headache, upset stomach, concentration or general discomfort.

Table 2. Blood Pressures and Resting heart Rates

\begin{tabular}{lllllll}
\hline $\begin{array}{l}\text { Treatment } \\
\text { Variable }\end{array}$ & Placebo & T2 & T3 & T4 & T5 & P-Value $^{1}$ \\
\hline SYSTOLIC & & & & & & \\
Baseline & $122.9(17.7)$ & $120.5(14.5)$ & $120.0(12.3)$ & $117.9(14.4)$ & $125.6(12.6)$ & 0.794 \\
Ending & $123.3(18.3)$ & $120.3(9.0)$ & $120.9(11.4)$ & $119.3(15.5)$ & $130.8(10.2)$ & 0.317 \\
DIASTOLIC & & & & & & \\
Baseline & $71.3(6.9)$ & $73.8(6.4)$ & $77.0(6.3)$ & $72.7(9.8)$ & $76.9(6.4)$ & 0.316 \\
Ending & $75.0(9.1)$ & $74.6(8.3)$ & $75.5(10.0)$ & $71.8(10.0)$ & $75.3(7.8)$ & 0.891 \\
HEART RATE & & & & & \\
Baseline & $64.5(11.2)$ & $72.3(5.1)$ & $70.0(14.0)$ & $71.6(13.3)$ & $69.4(6.4)$ & 0.518 \\
Ending & $62.7(9.4)$ & $71.6(6.7)$ & $65.7(9.0)$ & $68.6(9.5)$ & $68.0(8.4)$ & 0.206
\end{tabular}

${ }^{1}$ ANOVA. Placebo: V-8 juice only, T2: $50 \mathrm{mg}$ of $p$-synephrine (Advantra $\mathrm{Z}^{\circledR}$ ). T3: $p$-synephrine $+600 \mathrm{mg}$ naringin. T4: $p$-synephrine $+600 \mathrm{mg}$ naringin $+100 \mathrm{mg}$ hesperidin. T5: $p$-synephrine $+600 \mathrm{mg}$ naringin $+1,000 \mathrm{mg}$ hesperidin. Each value is the mean with the standard deviation for 10 subjects.

Table 3. Mean changes from baseline in each rating for placebo and each treatment group with $p$ values for between groups comparisons between placebo and treatment groups.

\begin{tabular}{|c|c|c|c|c|c|c|c|c|c|c|c|}
\hline \multicolumn{12}{|c|}{ Mean Changes From Baseline } \\
\hline & 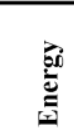 & $\begin{array}{l}\overline{\mathrm{E}} \\
\stackrel{\mathrm{E}}{\mathrm{E}}\end{array}$ & 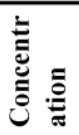 & 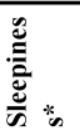 & 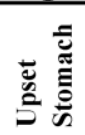 & 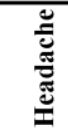 & 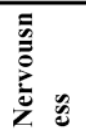 & $\frac{\vec{d}}{\stackrel{d}{a}}$ & $\stackrel{\Xi}{\frac{\Xi}{0}}$ & 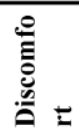 & \\
\hline 1=Placebo & 0.50 & 1.13 & -0.13 & 0.75 & 0.00 & 0.13 & -0.13 & 0.00 & -0.25 & 0.00 & 1=Placebo \\
\hline 2=Advantra $Z$ & 0.60 & 0.30 & 0.20 & 0.30 & 0.10 & 0.30 & 0.10 & 0.20 & -0.10 & 0.20 & $2=$ Advantra $Z$ \\
\hline $3=A Z+600 N$ & 0.38 & 0.00 & 0.38 & 1.00 & 0.00 & 0.00 & 0.00 & 0.00 & 0.00 & 0.00 & $3=A Z+600 N$ \\
\hline $4=A Z+100 H,+600 N$ & 0.75 & 0.88 & 0.25 & 0.63 & 0.13 & 0.13 & 0.00 & -0.13 & -0.38 & 0.00 & $4=A Z+100 H,+600 N$ \\
\hline $5=A Z+1000 H,+600 N$ & 0.33 & 0.56 & 0.00 & -0.11 & 0.33 & 0.00 & 0.11 & 0.22 & 0.22 & 0.22 & $5=A Z+1000 H,+600 N$ \\
\hline \multicolumn{12}{|c|}{ P Values for Comparisons Between Placebo \& Treatmet Groups } \\
\hline Placebo vs 2 & 0.84 & 0.21 & 0.45 & 0.40 & 0.39 & 0.52 & 0.17 & 0.20 & 0.43 & 0.39 & Placebo vs 2 \\
\hline Placebo vs 3 & 0.71 & 0.01 & 0.35 & 0.62 & $\mathbf{n} / \mathbf{v}$ & 0.33 & 0.33 & $\mathbf{n} / \mathbf{v}$ & 0.15 & $\mathbf{n} / \mathbf{v}$ & Placebo vs 3 \\
\hline Placebo vs 4 & 0.51 & 0.59 & 0.40 & 0.81 & 0.33 & 1.00 & 0.33 & 0.33 & 0.69 & 1.00 & Placebo vs 4 \\
\hline Placebo vs 5 & 0.68 & 0.29 & 0.79 & 0.09 & 0.36 & 0.57 & 0.18 & 0.36 & 0.28 & 0.36 & Placebo vs 5 \\
\hline
\end{tabular}




\section{Discussion}

Using a double-blinded, randomized, placebo-controlled protocol, this study compared the effects of $50 \mathrm{mg} p$-synephrine (as Advantra $Z^{\circledR}$ ) alone with three different amounts of hesperidin and naringin on: (1) resting metabolism rate, (2) blood pressure, (3) resting heart-rate, and (4) self-reported mood/energy levels in healthy human subjects. As expected, the RMR of the placebo group decreased over the $75 \mathrm{~min}$. test-retest period since subjects continued the 8-10 hour fast they began prior to the start of the study (Figure 1). The addition of $p$-synephrine, hesperidin, and naringin led to increases in RMR over placebo. However, while adding $100 \mathrm{mg}$ of hesperidin in Group 4 led to an increase in RMR over placebo, an unexpected reduction was observed in the RMR in Group 5 which received $1000 \mathrm{mg}$ hesperidin as compared to Group 4. These data indicate that increasing the hesperidin from $100 \mathrm{mg}$ to $1,000 \mathrm{mg}$ reversed some of the thermogenic effects of $100 \mathrm{mg}$ hesperidin in combination with $50 \mathrm{mg} p$-synephrine plus $600 \mathrm{mg}$ naringin. It may be that in this case, more is not better, and increasing the amount of hesperidin constitutes an example of hormesis [30, 31].

The increase in the metabolic rate between $p$-synephrine alone and the placebo control was approximately $6.9 \%$. This increase in thermogenesis is similar to the increases reported in previous studies involving $p$-synephrine $[17,18]$. The increase in RMR between Group 4, the combination of $p$-synephrine with $600 \mathrm{mg}$ naringin and $100 \mathrm{mg}$ hesperidin, and the placebo control is approximately $17.7 \%$. If one assumes that the product was taken twice a day for one year, the theoretical increase in calorie consumption would amount to over 31 pounds. However, the actual extent of weight loss if the product was consumed under these conditions remains to be determined.

The mechanism by which naringin and hesperidin increase the thermogenic effect of $p$-synephrine may involve enhancing the expression of adiponectin which is known to play a role in lipid and glucose metabolism. Liu et al. [32] have shown that naringenin and hesperetin up-regulate adiponectin expression, and both activate the peroxisome proliferator-activated receptor- $\gamma$ (PPARY) which has been recognized as the master regulator of adipocyte differentiation. In addition, naringenin also possessed significant ability to activate PPARa [32], a major regulator of lipid metabolism in the liver.

Products with thermogenic properties are frequently associated with elevated blood pressures and heart-rates. $p$-Synephrine is a phenylethylamine de- rivative with some structural similarities to ephedrine, and is thus assumed to exert cardiovascular effects by many authors [see for example, 20, 21, 33-35]. However, no effects on heart rate or blood pressure were observed in response to $p$-synephrine or $p$-synephrine in combination with naringin and hesperidin (Table 2). $p$-Synephrine differs from ephedrine in that it has a hydroxyl group on the para position of the benzene ring and lacks the methyl group on the side chain of the molecule. These structural differences greatly alter the pharmacokinetic and receptor binding properties of $p$-synephrine, resulting in little or no cardiovascular effects [27], as confirmed by this study. No adverse events have been directly attributable to bitter orange extract and $p$-synephrine $[36,37]$. However, caffeine is commonly present in products that contain $p$-synephrine $[19,28]$, and is well known to produce cardiovascular effects [38], particularly in caffeine-sensitive individuals [39].

The absence of changes in blood pressure, resting heart-rate and self-ratings in the four treatment groups involving $p$-synephrine, naringin and hesperidin relative to the placebo group is very positive, and in conjunction with the increased thermogenesis may result in the development of beneficial products with respect to weight loss and weight management. The findings were further substantiated by consistency of the results across all four treatment groups. However, longer term studies are required to assess the amount of weight that is actually lost in response to these products, and to provide information concerning safety when used over an extended period of time.

A problem faced in studies of thermogenic effects is that noticeable changes in the mood states listed in Table 1 often make subjects aware of whether or not they are receiving a placebo, thus undermining blinding of the study. The lack of significant differences between the treatment groups and the control group with respect to the self-report ratings of symptoms increases confidence in the safety of the combination as well as in the blinding procedure used in this study.

Strengths of the study are the use of randomized placebo-controlled double-blinded study design, the absence of thermogenic changes in the placebo group, the absence of adverse effects on blood pressure, heart-rate and self-reports in the four treatment groups, the consistency of the effects of $p$-synephrine on metabolism in all treatment groups, and the increases in RMR in the treatment groups. The weakness of this study is the small number (10) of subjects in the placebo and in each of the treatment groups. The study also reveals an interesting effect with re- 
spect to hesperidin where an increased amount may lead to a masking of the thermogenic effects found with lesser amounts.

\section{Conclusions}

This randomized double-blinded placebo control pilot study supports the safety and thermogenic effects of $p$-synephrine, particularly when combined with $600 \mathrm{mg}$ of naringin and $100 \mathrm{mg}$ of hesperidin. No increase in heart rate or blood pressure was observed over the $75 \mathrm{~min}$. of the study nor were there any differences in a self-reported rating of 10 common symptoms between the treated and placebo groups. The data suggests the combination of the flavonoids naringin and hesperidin with $p$-synephrine may assist weight management. Further studies are required to determine optimal doses as well as safety and efficacy associated with long term use.

\section{Acknowledgements}

This study was supported by a grant from $\mathrm{Nu}$ tratech Inc., West Caldwell, NJ.

\section{Conflict of Interest}

HM is an employee of Nutratech, Inc. SJS and GHP have served as consultants for Nutratech, Inc.

\section{References}

1. Nogata $Y$, Sakamoto K, Shiratsuchi H, et al. Flavonoid composition of fruit tissues of Citrus species. Biosci Biotechnol.Biochem. 2006; 70: 178-192.

2. Nielson IL, Chee WSS, Poulson L, et al. Bioavailability is improved by enzymatic modification of the citrus flavonoid hesperidin in humans: A randomized, double blind, crossover trial. J Nutr. 2006; 136: 404-408.

3. Bredsdorff L, Nielson IL, Rasmussen SE, et al. Absorption, conjugation and excretion of the flavonones, naringenin and hesperetin from alpha-rhamnosidase-treated orange juice in human subjects. Brit J Nutr. 2010; 103: 1602-1609.

4. Erlund I, Meririnne E, Alfthan G, et al. Plasma kinetics and urinary excretion of the flavonones naringenin and hesperetin in humans after ingestion of orange juice and grapefruit juice. J Nutr. 2001; 131: 235-241.

5. Erlund I, Silaste ML, Alfthan G, et al. Plasma concentrations of the flavonoids hesperetin, naringenin and quercetin in human subjects following habitual diet, and diets high or low in fruit and vegetables. Eur J Clin Nutr. 2001; 56: 891-898.

6. Manach C, Morand C, Gil-Izquierdo A, et al. Bioavailability in humans of the flavanones hesperidin and naringin after the ingestion of two doses of orange juice. Eur J Clin Nutr. 2003; 57: 235-2423.

7. Kanaze FI, Bounartzi MI, Georgarakis M, et al. Pharmakokinetics of the citrus flavanone aglycones hesperetin and naringenin after single oral administration in human subjects. Eur J Clin Nutr. 2007; 61: 472-477.

8. Krogholm KS, Bredsdorff L, Knuthsen P, et al. Relative bioavailability of the flavonoids quercetin, hesperetin and naringenin given simultaneously through diet. Eur J Clin Nutr. 2010; 64: 432-435.
9. Mulvihill EE, Allister EM, Sutherland BG, et al. Naringenin prevents dyslipidemia, apolipoprotein $\mathrm{B}$ overproduction, and hyperinsulinemia in LDL receptor-null mice with diet induced insulin resistance. Diabetes 2009; 58: 2198-2210.

10. Kim HK, Jeong TS, Lee MK, et al. Lipid lowering efficacy of hesperetin metabolites in high-cholesterol fed rats. Clin Chim Acta 2003; 327: 129-137.

11. Bok SH, Lee SH, Park YB, et al. Plasma and hepatic cholesterol and hepatic activities of 3-hydroxy-3-methyl-glutaryl- CoA reductase and acyl CoA: cholesterol transferase are lower in rats fed citrus peel extract or a mixture of citrus bioflavonoids. J Nutr. 1999; 129: 1182-1185.

12. Ghanim H, Mohanty P, Chaudhuri A, et al. Orange juice or fructose intake does not induce oxidative and inflammatory response. Diabetes Care 2007; 30: 1406-1411.

13. Ghanim H, Sai CL, Upadhyay M, et al. Orange juice neutralizes the proinflammatory effect of a high-fat, high-carbohydrate meal and prevents endotoxin increase and Toll-like receptor expression. Amer J Clin Nutr. 2010; 91: 940-949.

14. Pari L and Shagirtha K. Hesperetin protects against oxidative stress related hepatic dysfunction by cadmium in rats. Exptl Toxicol Pathol 2010; in press.

15. Kumar A, Dogra S, Prakash A. Protective effect of naringin, a citrus flavonoid, against colchicine-induced cognitive dysfunction and oxidative damage in rats. J Med Food 2010; 13: 976-984.

16. Arch JR. $\beta_{3}$-Adrenoceptor agonists: potential, pitfalls and progress. Eur J Pharmacol. 2002; 440: 99-107.

17. Gougeon R, Harrigan K, Tremblay JF. Increase in the thermic effect of food in women by adrenergic amines extracted from Citrus aurantium. Obesity Res. 2005; 13: 1187-1194.

18. Sale, C., Harris RC, Delves S, et al. Metabolic and physiological effects of ingesting extracts of bitter orange, green tea and guarana at rest and during treadmill walking in overweight males. Int J Obesity, 2006; 30: 764-773.

19. Stohs SJ, Shara M. A review of the safety and efficacy of Citrus aurantium in weight management. In: Bagchi D and Preuss H, eds. Obesity: Epidemiology, Pathophysiology and Prevention. Boca Raton, FL: CRC Press. 2007: 371-382.

20. Haaz S, Fontaine KR, Cutter G, Limdi N, et al. Citrus aurantium and synephrine alkaloids in the treatment of overweight and obesity: an update. Obesity Rev. 2006; 7: 79-88.

21. Haller CA, Benowitz NL, Peyton J III. Hemodynamic effects of ephedra-free weight-loss supplements in humans. Amer J Med. 2005; 118: 998-1003.

22. Pellati F, Benvenuti S, Melegari M. High-pressure liquid chromatography methods for the analysis of adrenergic amines and flavanones in Citrus aurantium L. var. amara. Phytochem Anal. 2002;15:220-225.

23. Pellati F, Benvenuti S, Melegari M, et al. Determination of adrenergic agonists from extracts and herbal products of Citrus aurantium L. var. amara by LC. J Pharmaceut Biomed Anal. 2004; 29: 1113-1119.

24. Roman MC, Betz JM, Hildreth J. Determination of synephrine in bitter orange raw materials, extracts, and dietary supplements by liquid chromatography with ultraviolet detection: single laboratory validation. J Amer Org Anal Chemists Int.2007; $90: 68-81$.

25. Mercolini L, Mandrioli R, Trere T,et al. Fast CE analysis of adrenergic amines in different parts of Citrus aurantium fruit and dietary supplements. J Sep Sci. 2010; 32: 1-8.

26. Dragull K, Breksa AP, Cain B. Synephrine content of juice from Satsuma mandarins (Citrus unshiu Marcovitch). J Agric.Food Chem. 2008; 56: 8874-8878.

27. Stohs SJ, Preuss HG. The safety of bitter orange (Citrus aurantium) and $p$-synephrine. HerbalGram 2011; 89: 34-39.

28. Inchiosa MAJr. Evidence (mostly negative) with the use of sympathomimetic agents for weight loss. J Obesity 2011; Epub. 
29. Kaats GR, Preuss HG, Leckie RB. Comparative effectiveness research (CER): opportunities and challenges for the nutrition industry. J Amer Coll Nutr. 2009; 28: 234-237.

30. Calabrese EJ. Hormesis is central to toxicology, pharmacology and risk assessment. Hum Exptl Toxicol.2010; 29: 249-261.

31. Calabrese V, Cornelius C, Trovato A, et al. The hormetic role of dietary antioxidants in free radical-related diseases. Curr Pharm Des. 2010; 16: 877-883.

32. Liu L, Shan S, Zhang K, et al. Naringenin and hesperetin, two flavonoids derived from Citrus aurantium up-regulate transcription of adiponectin. Phytother Res. 2008; 22: 1400-1403.

33. Bent S, Padula A, Neuhaus J. Safety and efficacy of Citrus aurantium for weight loss. Amer J Cardiol 2004; 94: 1359-1361.

34. Fugh-Berman A, Myers A. Citrus aurantium, an ingredient of dietary supplements marketed for weight loss: current status of clinical and basic research. Exptl Biol Med. 2004; 229: 698-704.

35. Haller CA, Duan M, Jacob III P, et al. Human pharmacology of a performance-enhancing dietary supplement under resting and exercise conditions. Brit J Clin Pharmacol. 2008; 65:833-840.

36. Stohs SJ. Assessment of the adverse event reports associated with Citrus aurantium (bitter orange) from April 2004 to October 2009. J Funct Foods, 2010; 2: 235-239.

37. McGuffin M. Media spins numbers on bitter orange AERs based on erroneous information from FDA. HerbalGram, 2006; 69: $52-54$

38. Riksen NP, Smits P, Rongen GA. The cardiovascular effects of methylxanthines. Handb Exptl Pharmacol. 2011; 200: 413-437.

39. Yang A, Palmer AA, DeWit H. Genetics of caffeine consumption and responses to coffee. Psychopharmacol. 2010; 211: 245-257. 